\title{
Ethanol Reversal of Oxycodone Tolerance in Dorsal Root Ganglia Neurons
}

\author{
Joanna C. Jacob, Kensuke Sakakibara, Ryan A. Mischel, Graeme Henderson, \\ William L. Dewey, and Hamid I. Akbarali \\ Department of Pharmacology and Toxicology, Virginia Commonwealth University, Richmond, Virginia (J.C.J., K.S., R.A.M., W.L. \\ D., H.I.A.); and School of Physiology, Pharmacology and Neuroscience, University of Bristol, Bristol, United Kingdom (G.H.)
}

Received September 29, 2017; accepted February 8, 2018

\begin{abstract}
Oxycodone is a semisynthetic opioid compound that is widely prescribed, used, and abused today, and has a well-established role in shaping the current opioid epidemic. Previously, we have shown that tolerance develops to the antinociceptive and respiratory depressive effects of oxycodone in mice, and that a moderate dose of acute ethanol or a protein kinase $C$ (PKC) inhibitor reversed that tolerance. To investigate further if tolerance was occurring through neuronal mechanisms, our aims for this study were to assess the effects of acute and prolonged oxycodone in isolated dorsal root ganglia (DRG) neurons and to determine if this tolerance was reversed by either ethanol or a PKC inhibitor. We found that an acute exposure to $3 \mu \mathrm{M}$ oxycodone reduced neuronal excitability, as measured by increased threshold potentials and reduced action potential amplitude, without eliciting measurable changes in resting
\end{abstract}

membrane potential. Exposure to $10 \mu \mathrm{M}$ oxycodone for 18 24 hours prevented oxycodone's effect on neuronal excitability, indicative of tolerance development. The development of opioid tolerance was mitigated in DRG neurons from $\beta$-arrestin 2 knockout mice. Oxycodone tolerance was reversed in isolated DRG neurons by the acute application of either ethanol $(20 \mathrm{mM})$ or the PKC inhibitor, bisindolylmaleimide XI hydrochloride (Bis XI), when a challenge of $3 \mu \mathrm{M}$ oxycodone significantly reduced neuronal excitability following prolonged exposure. Through these studies, we concluded that oxycodone acutely reduced neuronal excitability, tolerance developed to this effect, and reversal of that tolerance occurred at the level of a single neuron, suggesting that reversal of oxycodone tolerance by either ethanol or Bis XI involves cellular mechanisms.

\section{Introduction}

Oxycodone is a semisynthetic opioid that has potent analgesic properties. It was initially recommended to physicians as a highly effective opioid with reduced abuse liability and tolerance development. As we now know, oxycodone contributed substantially to the current opioid epidemic, unmasking its high abuse potential along with dependence and tolerance development. Opioid abusers are often poly-drug abusers, with ethanol being the most widely co-abused substance among these individuals. We have previously reported that ethanol reversed various morphine tolerances in vivo and in vitro (Hull et al., 2013; Llorente et al., 2013; Hill et al., 2016). In addition, we recently reported that ethanol also effectively reversed oxycodone antinociceptive tolerance in vivo (Jacob et al., 2017) as well as respiratory depression (R. Hill (R.H.) and G. Henderson (G.H.), personal communication). It has also been reported that inhibitors of protein

This work was supported by the National Institutes of Health National Institute of Drug Abuse [Grants T32 DA007027, RO1 DA036975, and P30 DA033934].

https://doi.org/10.1124/mol.117.110775. kinase $\mathrm{C}(\mathrm{PKC})$ reversed tolerance to the antinociceptive (Javed et al., 2004; Smith et al., 2007) and respiratory depressive effects of morphine, but not methadone (Withey et al., 2017). Today, oxycodone is still prescribed in various formulations, such as Oxycontin and Percocet, supporting the fact that it is critical to further our understanding of the interactions that occur when ethanol or other drugs known to inhibit PKC are consumed with oxycodone.

Evidence supporting the hypothesis that spinal mechanisms may mediate antinociceptive tolerance to opioids was introduced over 20 years ago (Gutstein and Trujillo, 1993). However, until recently tolerance has primarily been described and studied as a central phenomenon, with little attention directed toward potential peripheral contributions. There has been renewed interest in peripheral mechanisms of opioid tolerance, with a recent study suggesting that while the analgesic effects of morphine are mediated centrally, the signaling mechanisms underlying tolerance are distinctly different, and occur primarily outside the brain and spinal cord (Corder et al., 2017). This conclusion was based, in part, on the observation that following the administration of a peripherally restricted opioid antagonist, the initiation of opioid tolerance

ABBREVIATIONS: $A P$, action potential; $\beta$-arr2, $\beta$-arrestin 2; Bis XI, bisindolylmaleimide XI hydrochloride [3-[8-[(dimethylamino)methyl]-6,7,8,9tetrahydropyrido[1,2-a]indol-10-yl]-4-(1-methyl-1H-indol-3-yl)-1H-pyrrole-2,5-dione, monohydrochloride]; CTAP, D-phenylalanyl-L-cysteinyl-Ltyrosyl-D-tryptophyl-L-arginyl-L-threonyl-3-mercapto-L-valyl-cyclic $(2 \rightarrow 7)$-disulfide-L-threoninamide; DRG, dorsal root ganglia; KO, knockout; \% MPE, percentage of maximum possible effect; PKC, protein kinase C; TTX, tetrodotoxin; WT, wild type. 
was prevented, without affecting the antinociceptive effects in mice. A recent review covering the aforementioned study along with other related studies collectively suggested presynaptic $\mu$-opioid receptors in afferent nociceptors are necessary for the development of tolerance to opioids (Puig and Gutstein, 2017).

We have demonstrated that the acute effects of morphine, initially on enteric neurons (Smith et al., 2012), followed soon after on dorsal root ganglia (DRG) neurons (Ross et al., 2012), result in an increase in threshold potential, a decrease in action potential (AP) amplitude, and altered sodium channel kinetics, as indicated by a shift to the left in the inactivation curve suggesting reduced sodium channel availability. We have since published that tolerance to morphine can be evaluated in DRG neurons by examining these measures of neuronal excitability (Kang et al., 2017). Given that we now have a reproducible model to evaluate neuronal tolerance, we hypothesized that oxycodone would produce similar responses to morphine. Also, by utilizing the concept that the DRG serve as a relay station between the external nociceptive stimuli and the central nervous system, we further evaluated the argument that tolerance to opioids involves peripheral $\mu$-opioid receptors by demonstrating that tolerance occurs within the afferent cell bodies themselves.

The studies described in this paper were designed to assess the acute effects of oxycodone on DRG neurons and to determine whether tolerance developed to those effects. We then evaluated whether ethanol reversed the tolerance to oxycodone in these isolated neurons, as it did in the whole animal. We further investigated whether the reversal of oxycodone tolerance in this assay by ethanol was due to an interaction of the opioid and ethanol on PKC.

\section{Materials and Methods}

Drugs and Chemicals. Dulbecco's modified Eagle's medium, Hanks' balanced salt solution, and fetal bovine serum were purchased from Gibco (Grand Island, NY). Papain was purchased from Worthington Biochemical Corporation (Lakewood, NJ). B27 supplement, L-glutamate, and pencillin/streptomycin were purchased from Invitrogen (Carlsbad, CA). Glial cell line-derived neurotrophic factor was purchased from Neuromics (Edina, MN). Glass cover slips were purchased from ThermoFisher Scientific (Waltham, MA). Laminin was purchased from BD Biosciences (San Jose, CA) and poly-D-lysine was purchased from MP Biomedicals (Solon, OH). Twenty four-well cell culture dishes were purchased from CELLTREAT (Pepperell, MA). Collagenase from Clostridium histolyticum, magnesium chloride, calcium chloride, $\mathrm{NaCl}, \mathrm{KCl}, \mathrm{HEPES}, \mathrm{EGTA}$, sodium dihydrogen phosphate, glucose, ATP disodium salt, K-aspartic acid, potassium hydroxide, and sodium hydroxide were purchased from Sigma Aldrich (St. Louis, MO). Ethanol was obtained from AAPER Ethanol and Chemical Co. (Shelbyville, KY). Oxycodone $\mathrm{HCl}$ and morphine sulfate pentahydrate were obtained from the National Institutes of Health National Institute on Drug Abuse (Bethesda, MD) and dissolved in double distilled $\mathrm{H}_{2} 0$. Bisindolylmaleimide $\mathrm{XI}$ hydrochloride (Bis $\mathrm{XI}$ ) and naloxone $\mathrm{HCl}$ were purchased from Sigma Aldrich. D-phenylalanyl-L-cysteinyl-L-tyrosyl-D-tryptophylL-arginyl-L-threonyl-3-mercapto-L-valyl-cyclic $(2 \rightarrow 7)$-disulfide-Lthreoninamide (CTAP) was purchased from Cayman Chemical (Ann Arbor, MI).

Animals. Adult male C57/BL6, 25-30 g and at least 6 weeks of age, were purchased from ENVIGO (Frederick, MD). $\beta$-Arrestin 2 ( $\beta$-arr2) wild-type (WT) and knockout (KO) male mice (25-30 g) were obtained from Dr. Lefkowitz (Duke University, Durham, NC). All animals were housed up to five per cage in animal care quarters and maintained at $22^{\circ} \mathrm{C} \pm 2{ }^{\circ} \mathrm{C}$ on a 12 -hour light-dark cycle. Access to food and water was available ad libitum. Protocols and procedures were approved by the Institutional Animal Care and Use Committee at Virginia Commonwealth University Medical Center and comply with the recommendations of the International Association for the Study of Pain (https:// www.iasp-pain.org).

Tail Immersion Test. The warm water tail immersion test was performed by using a water bath stabilized at $56^{\circ} \mathrm{C} \pm 0.1^{\circ} \mathrm{C}$, utilizing the Coderre and Rollman (1983) method. A baseline (control) tail withdrawal latency was determined prior to any injections, and qualifying responses occurred between 2.0 and 4.0 seconds. Test latencies were capped at 10.0 seconds to avoid tissue damage. Antinociception was quantified as the percentage of maximum possible effect (\% MPE) and calculated for each mouse, using the following equation: \% MPE $=[$ (test latency - baseline latency)/(maximum latency - baseline latency)] $\times$ 100 (Harris and Pierson, 1964).

Single-Day Tolerance Model. $\beta$-arr2 WT male mice were weighed and baseline tail withdrawal latencies (seconds) were assessed in the tail immersion test. Twenty minutes following an initial injection of an $\mathrm{ED}_{80}$ dose of oxycodone $(1.25 \mathrm{mg} / \mathrm{kg}$, s.c.) mice were tested for antinociception, and that latency was recorded as the acute response. Forty minutes later, mice received the second of their eight total injections, followed by the remaining six injections, each given 1 hour apart. Twenty minutes following the eighth and final injection, animals were again tested for tail withdrawal latencies and this value was recorded as the chronic response. Pretreatment times and injection schedules were based on previous methods used in our laboratory (Jacob et al., 2017).

Isolation and Culture of Primary Cells from Adult Mouse Dorsal Root Ganglia. DRGs from the adult mouse were prepared as previously described (Ross et al., 2012). Mice were sacrificed via $\mathrm{CO}_{2}$ inhalation followed by cervical dislocation. L5-S1 DRGs were immediately harvested under a dissecting microscope and placed in a dish containing Hanks' balanced salt solution. Papain (15 U/ml) was then added to the dish and incubated for 18 minutes at $37^{\circ} \mathrm{C}$. Subsequently, ganglia were transferred to a separate dish containing Hanks' balanced salt solution and $1.5 \mathrm{mg} / \mathrm{ml}$ collagenase from Clostridium histolyticum and incubated for 60 minutes at $37^{\circ} \mathrm{C}$. After incubation, ganglia were transferred to Dulbecco's modified Eagle's medium in a sterile $15 \mathrm{ml}$ conical flask, dissociated by triturating, and centrifuged for 5 minutes at $1000 \mathrm{rpm}$. The supernatant was discarded and the pellet was resuspended in neurobasal A media containing $1 \%$ fetal bovine serum, $1 \times \mathrm{B}-27$ supplement, $10 \mathrm{ng} / \mathrm{ml}$ glial cell line-derived neurotrophic factor, $2 \mathrm{mM}$ L-glutamine, and $100 \mathrm{U} / \mathrm{ml}$ penicillin/ streptomycin/amphotericin B (complete neuron media). Isolated cells were plated on laminin and poly-D-lysine-coated glass cover slips and maintained at $37^{\circ} \mathrm{C}$ in a humidified $5 \% \mathrm{CO}_{2}$ /air incubator. Where indicated, isolated neurons were exposed to $10 \mu \mathrm{M}$ oxycodone or morphine in complete neuron media for 18-24 hours prior to wholecell patch-clamp experiments.

Electrophysiology. Patch micropipettes were pulled from 1.5/0.84 o.d./i.d. ( $\mathrm{mm}$ ) borosilicate glass capillaries (World Precision Instruments, Sarasota, FL) on a Flaming/Brown Micropipette puller P97 (Sutter Instruments, Novato, CA) and fire polished. Initial pipette resistances were 2-4 $\mathrm{M} \Omega$ when filled with filtered internal solution containing $100 \mathrm{mM}$ L-aspartic acid (K salt), $30 \mathrm{mM} \mathrm{KCl}, 4.5 \mathrm{mM}$ $\mathrm{Na}_{2} \mathrm{ATP}, 1 \mathrm{mM}$ magnesium chloride, $10 \mathrm{mM}$ HEPES, and $0.1 \mathrm{mM}$ EGTA (pH adjusted to 7.2). Current-clamp experiments were conducted by transporting coverslips containing adhered DRG neurons to a microscope stage plate and superfusing with HEPES-buffered external solution containing $135 \mathrm{mM} \mathrm{NaCl}, 5.4 \mathrm{mM} \mathrm{KCl}, 0.33 \mathrm{mM}$ sodium dihydrogen phosphate, $5 \mathrm{mM}$ HEPES, $1 \mathrm{mM}$ magnesium chloride, $2 \mathrm{mM}$ calcium chloride, and $5 \mathrm{mM}$ glucose ( $\mathrm{pH}$ adjusted to 7.4 with sodium hydroxide). Because small-diameter neurons correspond to nociceptive $\mathrm{A} \delta$ fiber and C-type neurons, only small neurons $(<30$ $\mathrm{pF}$ capacitance) were used $(\mathrm{pF}=16.06 \pm 0.64, n=64)$ (Abraira and Ginty, 2013; Barabas et al., 2014). Whole-cell current-clamp recordings were made at room temperature using an Axopatch 200B 

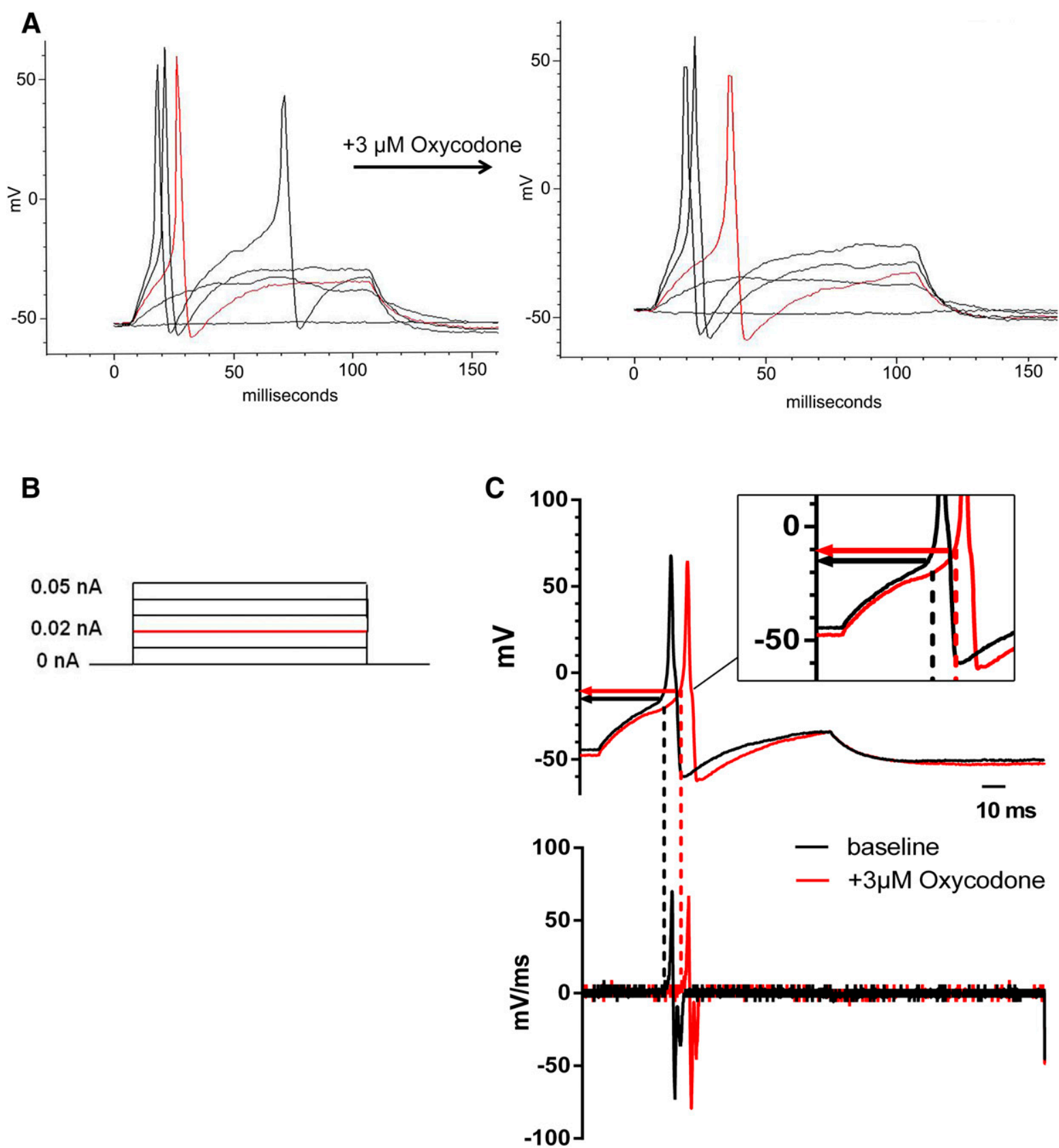

Fig. 1. Acute oxycodone reduced neuronal activity. (A) Raw traces representing neuronal activity before and 10 minutes following $3 \mu \mathrm{M}$ oxycodone, with the associated protocol showing a stepwise increase in current injection corresponding to the initiation of APs (red bar) (B). (C) Initial AP traces resulting from minimum necessary current injection before (black) and after (red) $3 \mu \mathrm{M}$ oxycodone, along with dV/dt traces exhibiting extrapolation of threshold potential values.

amplifier (Molecular Devices, Sunnyvale, CA), with a set protocol consisting of $0.01 \mathrm{nA}$ steps beginning at $-0.03 \mathrm{nA}$ to assess both active and passive cell properties. Values reported did not reflect corrected junction potentials $(\sim-12 \mathrm{mV})$. Pulse generation and data acquisition were achieved with Clampex and Clampfit 10.2 software (Molecular Devices). AP derivatives were determined using the differential function in the Clampfit software by taking the derivative of the voltage with respect to time $(\mathrm{dV} / \mathrm{dT})$. Threshold potentials were defined as the voltage at which $\mathrm{dV} / \mathrm{dt}$ deviated significantly from zero during the course of an AP uprise. Assessment of acute oxycodone effects began after a 2 to 3 minute equilibration period, where an external solution containing $3 \mu \mathrm{M}$ oxycodone solution was then superfused over neurons. Threshold potentials were determined from the first derivatives of current clamp recordings taken at 1 minute intervals for 10 minutes following oxycodone exposure. The difference between threshold potential values at 0 and 10 minutes was calculated for each cell. Tolerance to oxycodone was assessed in an identical manner in cells that had been incubated overnight in media containing $10 \mu \mathrm{M}$ oxycodone. The effect of ethanol on oxycodone tolerance was assessed by incubating cells overnight in $10 \mu \mathrm{M}$ oxycodone followed by the addition of ethanol to the media [20 mM (final)] for 50 minutes immediately preceding whole-cell patch clamp recording. Bis XI was added to the prefiltered internal pipette solution at a final concentration of $100 \mathrm{nM}$ to investigate the role of PKC inhibition on oxycodone tolerance. Neurons were treated overnight with $10 \mu \mathrm{M}$ oxycodone and exposed to $100 \mathrm{nM}$ Bis XI immediately upon membrane breakthrough. Neurons were then superfused with external solution containing $3 \mu \mathrm{M}$ oxycodone. In all experiments, $N$ represents the total number of mice 


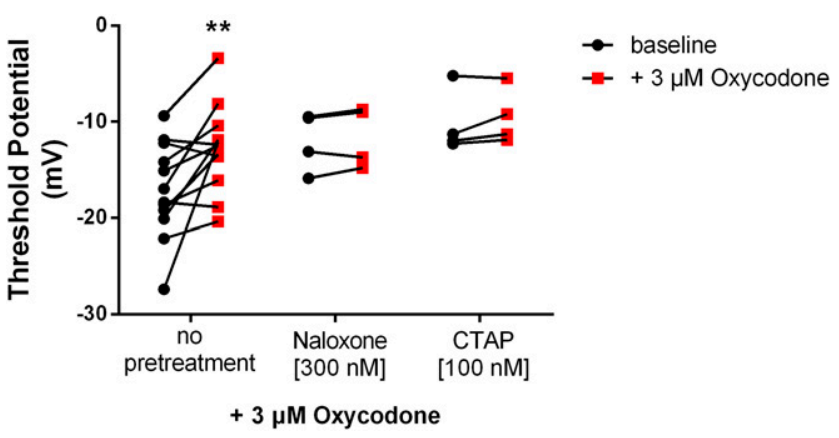

Fig. 2. Coadministration of naloxone or CTAP blocked the acute effects of oxycodone. DRG neurons were coperfused with external solution containing $3 \mu \mathrm{M}$ oxycodone and either $300 \mathrm{nM}$ naloxone (black) or $100 \mathrm{nM}$ CTAP (blue) for 10 minutes. Both naloxone $(N=2, n=4)$ and $\operatorname{CTAP}(N=2, n=4)$ prevented the ability of $3 \mu \mathrm{M}$ oxycodone to shift threshold potentials to a more positive value compared with acute oxycodone administration alone $* * P<0.01, P>0.05(P>0.05$, two-way repeated measures analysis of variance with Bonferroni's post-hoc test). Data represent individual changes in threshold potentials before $(\bullet)$ and 10 minutes after (red $\mathbf{a})$ oxycodone exposure.

and $n$ represents the total number of cells within each group from which recordings were obtained.

Data Analysis. Statistical differences were calculated using GraphPad Prism 5.0 (GraphPad Software, Inc., La Jolla, CA). All analyses were conducted on the small $n$ value, representing total cell numbers (except for Fig. $5 \mathrm{~A}$, where $N$ representing the number of mice was analyzed). Within-subject comparisons were analyzed via Student's paired $t$ test. For group comparisons, results were analyzed by two-way analysis of variance with Bonferroni post-hoc test and an alpha level set to 0.05 . The results are expressed as the mean \pm S.E.M. value, except where individual data points are shown.

\section{Results}

\section{Acute Oxycodone Reduced Neuronal Excitability}

It has been established that DRG neurons isolated from adult rats and mice express opioid receptors (Coggeshall et al., 1997; Wang et al., 2010; Stein, 2013) and studies from our own laboratory have shown various effects of morphine on DRG neurons isolated from adult mice (Ross et al., 2012; Kang et al., 2017). However, the effects of oxycodone on DRG neuronal excitability have yet to be investigated. Candidate neurons were selected for their round spherical shape and small size. Figure 1A shows a family of raw traces obtained with increasing current at baseline (left) and 10 minutes after $3 \mu \mathrm{M}$ oxycodone exposure (right). Following $3 \mu \mathrm{M}$ oxycodone, the number of APs at positive current $(2 \times$ rheobase) was reduced (Fig. 1A). A representative protocol showing the current injected and corresponding rheobase (outlined in red) is shown in Fig. 1B. Threshold potential values gradually increased to more positive potentials as exposure to oxycodone continued, with a noticeable increase beginning 5 minutes post oxycodone application. Continuous superfusion of the $3 \mu \mathrm{M}$ oxycodone bath for $10 \mathrm{~min}$ utes led to a $+4.58 \pm 1.39 \mathrm{mV}$ increase in threshold potential on average ( $P<0.01, N=7, n=12$ ) (Figs. 1C, 2 , and 9) and a decrease in AP amplitude by $8.33 \mathrm{mV}$ (Fig. $1 \mathrm{C}$; Table 1). This concentration of oxycodone was the minimal effective concentration to elicit acute opioid effects as determined by the two factors listed previously since 10-minute exposure to $1 \mu \mathrm{M}$ oxycodone did not result in significantly increased threshold potentials (data not shown). Other cell parameters such as peak AP height, input resistance, resting membrane potential, and rheobase were measured and analyzed, but no statistically significant changes were found after an acute $3 \mu \mathrm{M}$ oxycodone challenge (Table 1 ).

To determine if the acute effects of oxycodone on neuronal excitability were mediated by opiate receptors, we co-perfused external solution over neurons that contained $3 \mu \mathrm{M}$ oxycodone and $300 \mathrm{nM}$ naloxone. The addition of naloxone prevented the increase in threshold potentials observed after acute oxycodone alone $(-12.02 \pm 1.54 \mathrm{mV}$ vs. $-11.55 \pm 1.58 ; N=2, n$ $=4, P>0.05$ ) (Fig. 2). We further tested the hypothesis that $\mu$-opioid receptors specifically mediate oxycodone's effects in DRG neurons by utilizing the selective $\mu$-opioid receptor peptide antagonist CTAP. Similar to our naloxone experiments, we co-perfused neurons with an external solution containing $3 \mu \mathrm{M}$ oxycodone and $100 \mathrm{nM}$ CTAP for 10 minutes, which resulted in the lack of a shift in threshold potential $(-10.20 \pm 1.68 \mathrm{mV}$ vs. $-9.48 \pm 1.45 ; N=2, n=4, P>0.05)$ (Fig. 2). These findings suggest that in DRG neurons, oxycodone's effects are elicited selectively through the $\mu$-opioid receptor.

\section{TABLE 1}

Active and passive cell properties of DRG neurons in response to $3 \mu \mathrm{M}$ oxycodone

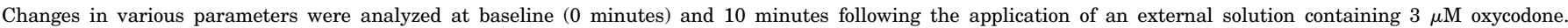

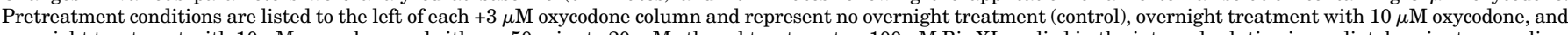

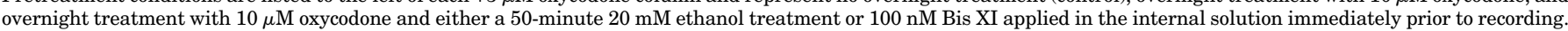

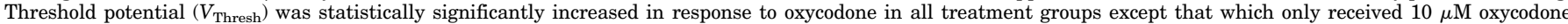

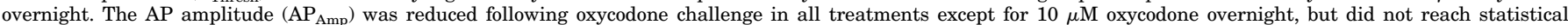

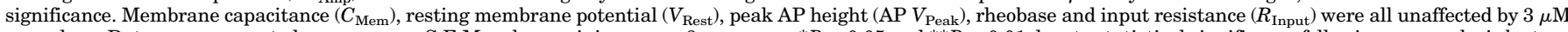

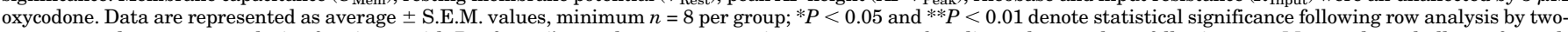

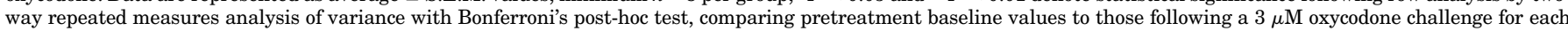
treatment group.

\begin{tabular}{|c|c|c|c|c|c|c|c|c|}
\hline Parameter & Control & $+3 \mu \mathrm{M}$ Oxy & $10 \mu \mathrm{M}$ Oxy & $+3 \mu \mathrm{M}$ Oxy & $10 \mu \mathrm{M} \mathrm{Oxy}+\mathrm{EtOH}$ & $+3 \mu \mathrm{M}$ Oxy & $10 \mu \mathrm{M}$ Oxy + Bis XI & $+3 \mu \mathrm{M}$ Oxy \\
\hline$C_{\mathrm{Mem}}(\mathrm{pF})$ & $17.31 \pm 1.47$ & & $13.45 \pm 2.01$ & & $13.38 \pm 1.15$ & & $19.26 \pm 1.66$ & \\
\hline$V_{\text {Rest }}(\mathrm{mV})$ & $-48.53 \pm 1.50$ & $-46.15 \pm 2.59$ & $-49.58 \pm 3.85$ & $-43.54 \pm 2.26$ & $-48.78 \pm 1.77$ & $-46.94 \pm 1.95$ & $-45.59 \pm 1.81$ & $-39.85 \pm 2.61$ \\
\hline $\begin{array}{l}\mathrm{AP} V_{\text {Thresh }} \\
\quad(\mathrm{mV})\end{array}$ & $-17.13 \pm 1.43$ & $-12.55 \pm 1.20^{* *}$ & $-23.77 \pm 3.79$ & $-23.18 \pm 3.72$ & $-16.19 \pm 1.44$ & $-12.44 \pm 2.32^{* *}$ & $-14.33 \pm 1.67$ & $-9.66 \pm 1.73^{*}$ \\
\hline $\begin{array}{l}\mathrm{AP} V_{\text {Peak }} \\
(\mathrm{mV})\end{array}$ & $64.46 \pm 1.67$ & $60.50 \pm 4.19$ & $62.50 \pm 6.79$ & $63.70 \pm 6.61$ & $61.33 \pm 2.78$ & $56.19 \pm 4.04$ & $62.76 \pm 2.86$ & $64.19 \pm 2.17$ \\
\hline $\begin{array}{l}\mathrm{AP}_{\mathrm{Amp}} \\
(\mathrm{mV})\end{array}$ & $81.59 \pm 1.78$ & $73.26 \pm 4.74$ & $87.86 \pm 9.17$ & $86.88 \pm 10.01$ & $76.07 \pm 3.36$ & $67.00 \pm 5.21$ & $77.09 \pm 2.82$ & $73.85 \pm 3.03$ \\
\hline $\begin{array}{l}\text { Rheobase } \\
\text { (nA) }\end{array}$ & $0.04 \pm 0.01$ & $0.06 \pm 0.01$ & $0.02 \pm 0.002$ & $0.03 \pm 0.02$ & $0.05 \pm 0.01$ & $0.03 \pm 0.01$ & $0.05 \pm 0.01$ & $0.04 \pm 0.01$ \\
\hline $\begin{array}{l}R_{\text {Input }} \\
\quad(\mathrm{M} \Omega)\end{array}$ & $1440.0 \pm 222.98$ & $1160.56 \pm 244.40$ & $1600.0 \pm 110.47$ & $1346.67 \pm 442.95$ & $1241.39 \pm 197.73$ & $1197.92 \pm 181.20$ & $1093.33 \pm 118.03$ & $782.08 \pm 118.88$ \\
\hline
\end{tabular}




\section{Overnight Exposure to Oxycodone Led to Tolerance}

Previously, we have shown tolerance to morphine in DRG neurons isolated from mice implanted with morphine pellets for 5 days (Kang et al., 2017). Here, we tested the hypothesis that prolonged exposure to oxycodone in vitro would lead to a tolerant phenotype. Neurons $(N=5, n=8)$ were incubated overnight (minimum 18 hours) with $10 \mu \mathrm{M}$ oxycodone prior to being moved to the microscope stage plate containing an external solution with no drug treatment. Baseline threshold recordings were not statistically different from untreated neurons, although a few showed some evidence of hyperexcitability. Following a 10-minute $3 \mu \mathrm{M}$ oxycodone bath challenge, these neurons did not exhibit changes in threshold potential $(-23.77 \pm 3.79 \mathrm{mV}$ vs. $-23.18 \pm 3.72 \mathrm{mV} ; P>0.05)$ (Figs. $3 \mathrm{~A}$ and 9) or $\mathrm{AP}$ amplitude $(-87.86 \pm 9.17 \mathrm{mV}$ vs. $86.88 \pm$ $10.01 \mathrm{mV}$ ) (Table 1), indicating the development of tolerance had occurred.

To further validate this model of tolerance, we tested the development of tolerance to oxycodone or morphine in DRG neurons isolated from WT and $\beta$-arr2 KO mice. Previous studies have shown that antinociceptive tolerance does not occur in $\beta$-arr2 $\mathrm{KO}$ mice. Morphine and oxycodone are opioid compounds that are known to recruit $\beta$-arr2, a scaffolding protein thought to contribute to their tolerance mechanisms (Bohn et al., 2000; Raehal and Bohn, 2011; Williams et al., 2013). Neurons isolated from $\beta$-arr2 KO mice and incubated overnight in $10 \mu \mathrm{M}$ oxycodone continued to respond to oxycodone the following day (Fig. 3B). Following a $3 \mu \mathrm{M}$ oxycodone challenge, neurons exhibited a $+2.93 \pm 1.15 \mathrm{mV}$ increase in threshold potential compared with baseline and did not display signs of tolerance to oxycodone (Fig. 3C, $P<$ $0.05 ; N=5, n=10$ ). We also tested morphine in B-arr2 WT and $\mathrm{KO}$ neurons, and like oxycodone, the shift in threshold potential in response to $3 \mu \mathrm{M}$ morphine was inhibited in WT neurons incubated overnight with $10 \mu \mathrm{M}$ morphine $(-26.13 \pm$ $3.00 \mathrm{mV}$ vs. $-25.55 \pm 2.68 \mathrm{mV} ; N=4, n=6$ ) (Fig. $4 \mathrm{~A}$ ). However, neurons isolated from $\beta$-arr2 $\mathrm{KO}$ mice continued to respond to a $3 \mu \mathrm{M}$ morphine challenge after overnight morphine exposure, as indicated by a $+4.38 \pm 0.55 \mathrm{mV}$ shift in threshold potential values (Fig. $4 \mathrm{~B}, P<0.05 ; N=4, n=6$ ), similar to our findings with oxycodone. Based on these results, we are confident that true cellular tolerance to oxycodone and morphine developed in vitro within an isolated DRG neuron following overnight exposure to $10 \mu \mathrm{M}$ of either opioid.

\section{In Vivo Exposure to Oxycodone Led to Ex Vivo Tolerance}

Previously, our laboratory has shown that antinociceptive tolerance developed to oxycodone using a single-day repeated injection model. Prior to this study, we had tested tolerance development using Swiss-Webster mice; however, in this study we investigated whether tolerance would develop to oxycodone in B-arr2 WT mice. In Swiss-Webster mice, the $\mathrm{ED}_{80}$ dose of oxycodone (subcutaneous) was $1.25 \mathrm{mg} / \mathrm{kg}$. Similarly, we found this dose produced acute antinociception
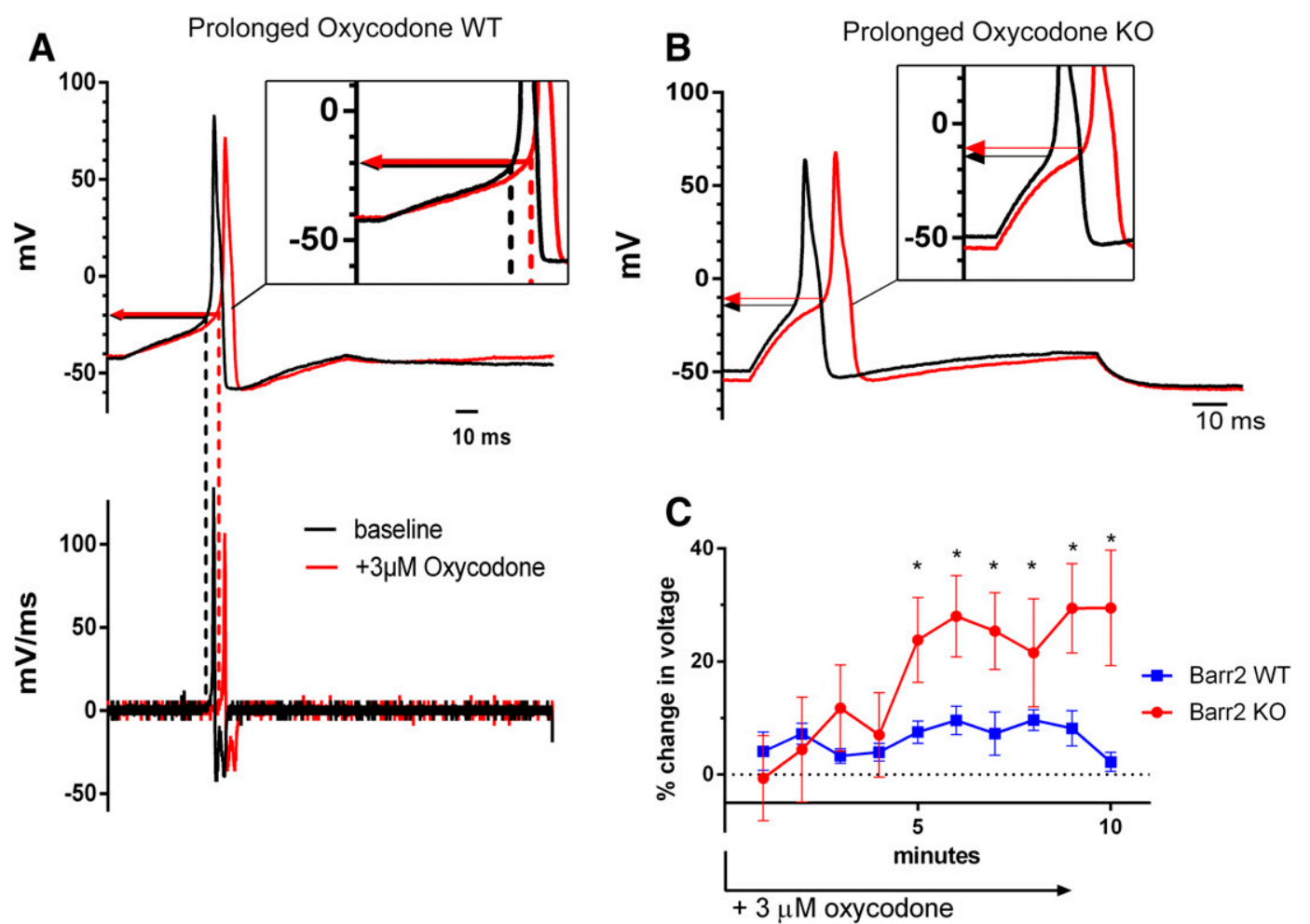

Fig. 3. Response to $3 \mu \mathrm{M}$ oxycodone in $\beta$-arr2 WT and KO DRG neurons with and without overnight treatment with oxycodone. (A) WT neurons incubated overnight in media treated with $10 \mu \mathrm{M}$ oxycodone did not respond to a $3 \mu \mathrm{M}$ oxycodone challenge, with no observed shift in threshold potential. (B) KO neurons incubated overnight in media treated with $10 \mu \mathrm{M}$ oxycodone continued to respond to a $3 \mu \mathrm{M}$ oxycodone challenge (red), as seen by the increase in threshold potential. (C) Threshold potential significantly increased in DRG neurons from Barr2 KO mice in response to $3 \mu \mathrm{M}$ oxycodone challenge following overnight incubation with $10 \mu \mathrm{M}$ oxycodone. Compared with WT neurons, percentage change in threshold potential from baseline values showed Barr2 KO DRG neurons increased nearly 40\%. Data were collected every minute for 10 minutes and represent mean \pm S.E.M. (Barr2 KO: $N=5, n=10$; WT: $N=5, n=8$ ). Data were analyzed using two-way analysis of variance with repeated measures, followed by Bonferroni's post-hoc test, with significance at $* P<0.05$. 

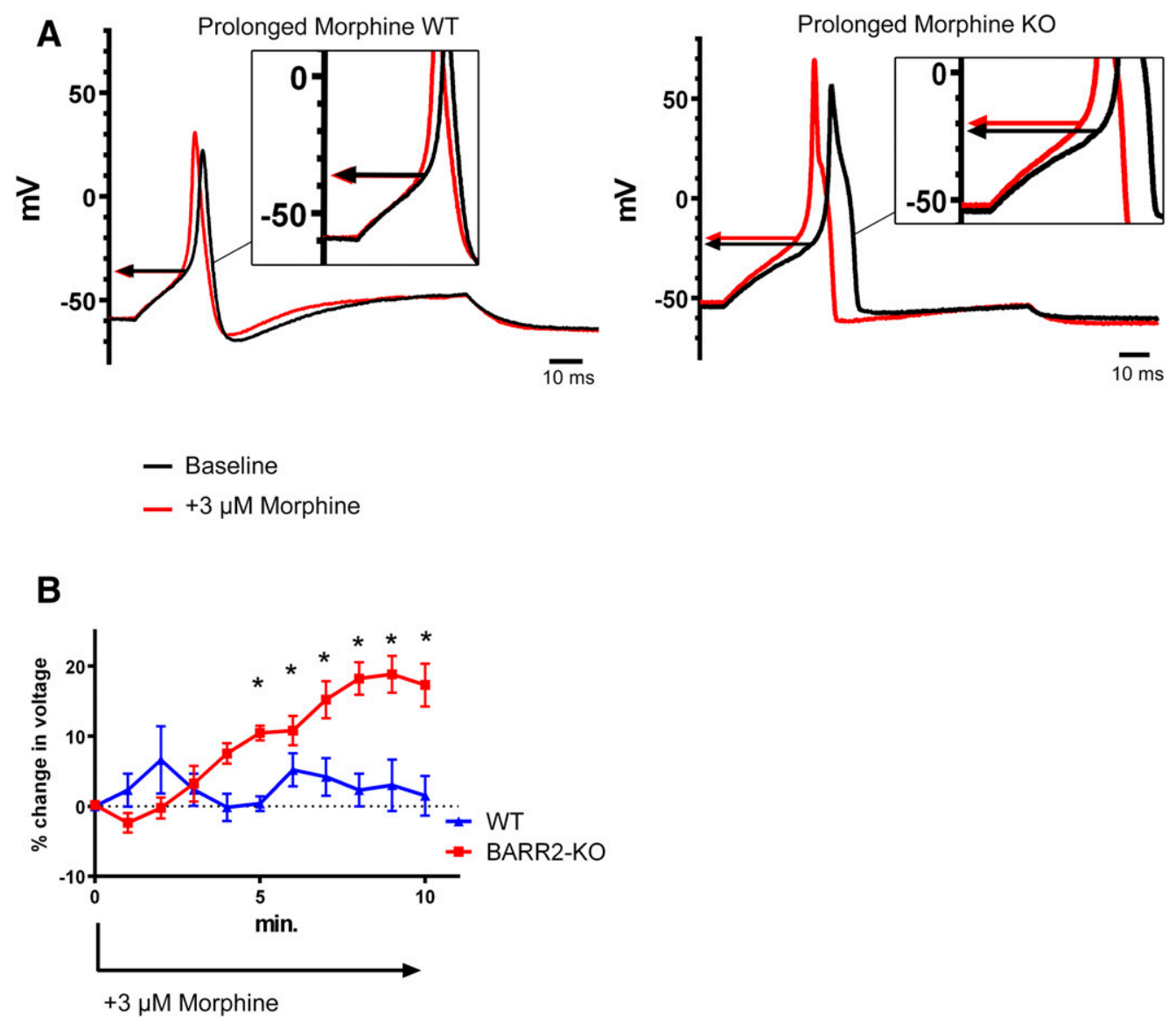

Fig. 4. Tolerance developed to morphine in $\beta$-arr2 WT, but not KO DRG neurons. Threshold potential of $10 \mu \mathrm{M}$ morphine-treated neurons from BARR2-KO mice, but not WT, was increased by $3 \mu \mathrm{M}$ morphine-containing external solution. In BARR2-KO neurons (A, right), threshold potential was increased in contrast to WT (A, left). Morphine $(3 \mu \mathrm{M})$ administered at time 0 led to increased threshold potential (B), which reached a plateau of approximately $20 \%$ increase 7 minutes after the administration in BARR2-KO. Data were collected every minute for 10 minutes and represent the mean \pm S.E.M. (BARR2 KO: $N=4, n=6$, WT: $N=4, n=6$ ). Data were analyzed using two-way analysis of variance with repeated measures, followed by Bonferroni's post-hoc test, with significance at $* P<0.05$.

in B-arr2 WTs $(N=4)$ with an average of $70.73 \% \pm 19.75 \%$ MPE. Following a total of eight repeated injections of oxycodone $(1.25 \mathrm{mg} / \mathrm{kg}$, s.c.), average antinociception was significantly reduced, equaling $10.20 \% \pm 4.25 \% \mathrm{MPE}(P<0.05)$ (Fig. 5A). Immediately following completion of the single-day tolerance model, mice were sacrificed and DRG neurons were isolated as described previously. No additional oxycodone was added to the media during the overnight incubation. The following day, neurons were assessed for their baseline threshold potential and subsequent response to a $3 \mu \mathrm{M}$ oxycodone bath challenge. The average baseline threshold was $11.22 \pm 1.61 \mathrm{mV}$. These neurons did not demonstrate an upward shift in threshold potential following the $3 \mu \mathrm{M}$ oxycodone challenge $(-12.43 \pm 1.90 \mathrm{mV})$, suggesting that the in vivo tolerance that developed persisted at the cellular level $(N=4, n=6 ; P>0.05)$ (Fig. 5B).

\section{Acute Ethanol Reversed Oxycodone Tolerance}

We next tested the hypothesis that acute exposure to ethanol would reverse tolerance induced by oxycodone. Following an overnight incubation in $10 \mu \mathrm{M}$ oxycodone, ethanol [20 $\mathrm{mM}]$ was added directly to the DRG neuron coverslips in the continued presence of $10 \mu \mathrm{M}$ oxycodone in the culture media. The cells were exposed to ethanol for 50 minutes to correspond to the amount of time ethanol was given to reverse oxycodone tolerance in vivo (Jacob et al., 2017). Neurons $(N=8, n=13)$ were initially exposed to an external bath solution without any drug treatments, and baseline recordings were obtained. Interestingly, we no longer observed the low threshold potentials indicative of the heightened excitability at baseline that was noted in the cells exposed only to $10 \mu \mathrm{M}$ oxycodone overnight. Cells were then exposed to a bath containing $3 \mu \mathrm{M}$ oxycodone for 10 minutes. Threshold potential values increased $+3.75 \pm 1.67 \mathrm{mV}$, from $-16.19 \pm 1.44$ to $-12.44 \pm 2.32 \mathrm{mV}(P<0.05)$, showing similar shifts observed under acute oxycodone conditions. The AP amplitude was also decreased from $76.07 \pm 3.3$ to $67.00 \pm 5.21 \mathrm{mV}$. These cells no longer displayed a tolerant phenotype, and the response to oxycodone indicated that acute exposure to ethanol reversed tolerance within a single neuron (Figs. 6 and 9). The same 50 -minute $20 \mathrm{mM}$ ethanol treatment had no effect on DRG neurons not exposed to oxycodone when assessed for changes in excitability over a 10 -minute time period $(-14.31 \pm 1.44 \mathrm{mV}$ vs. $-13.77 \pm 1.19 \mathrm{mV}$ ) (one-way analysis of variance, $P=0.88$, $N=2, n=7$ ) (Fig. 7), suggesting the effects observed in the neurons that were exposed to prolonged oxycodone and followed by ethanol were due specifically to oxycodone. 


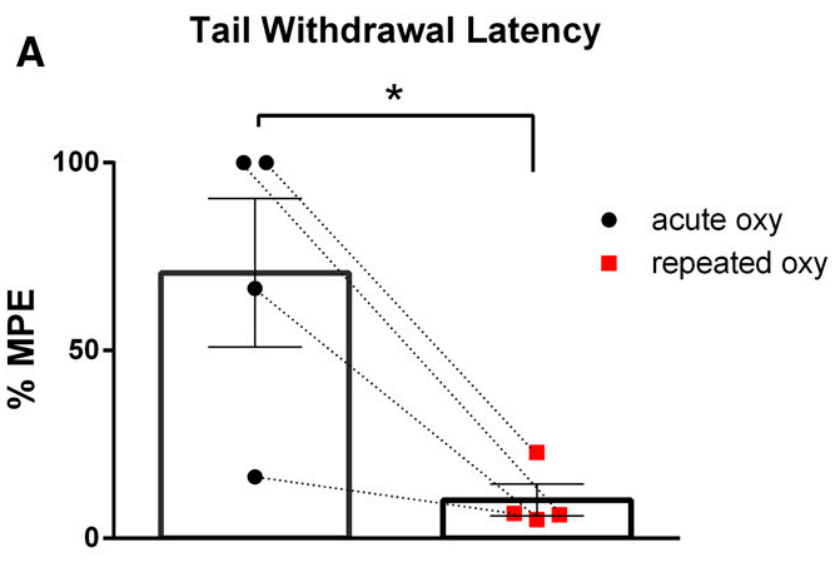

Oxycodone [1.25 mg/kg, s.c.]

B

\section{in vivo oxy-treated DRG neurons}

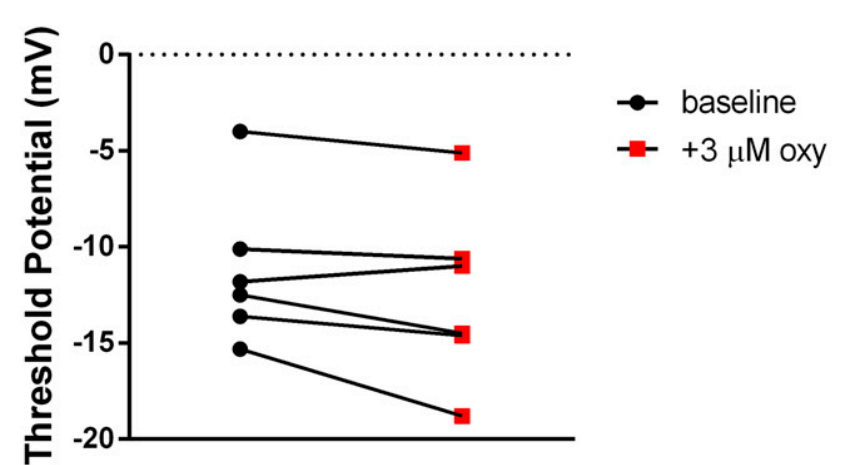

Fig. 5. DRG neurons remain tolerant to oxycodone following in vivo single-day tolerance model. (A) WT mice $(N=4)$ were tested for the development of tolerance to oxycodone using a single-day tolerance model. Repeated injections of oxycodone $(1.25 \mathrm{mg} / \mathrm{kg}$, s.c.) led to a significantly reduced antinociceptive response compared with the acute response (paired two-tailed Student's $t$ test, $* P<0.05, P<0.05$ ). (B) Threshold potential of DRG neurons from oxycodone-tolerant mice. No shift in threshold potential was observed in response to a bath challenge of $3 \mu \mathrm{M}$ oxycodone $(n=6)$ indicating that these neurons continued to demonstrate tolerance to oxycodone due to the repeated in vivo treatment alone (paired two-tailed Student's $t$ test, $P>0.05$ ).

The Investigation of the Mechanism of Ethanol Reversal Using an Inhibitor of PKC.

Inhibition of PKC rapidly reversed oxycodone tolerance. Various PKC inhibitors have also been reported to reverse tolerance to both the antinociceptive effects and the respiratory depressive effects of morphine in vivo (Smith et al., 2003; Javed et al., 2004; Hull et al., 2010; Withey et al., 2017). Additionally, we have implicated PKC inhibition in ethanol reversal of morphine tolerance in vitro in locus coeruleus neurons (Llorente et al., 2013). We tested the hypothesis that inhibiting PKC would also reverse oxycodone tolerance. DRG neurons ( $N=7, n=8)$ incubated overnight with $10 \mu \mathrm{M}$ oxycodone were transferred to the microscope stage plate and perfused with external bath solution. In these studies, the PKC inhibitor, Bis XI was added to the internal pipette solution at a final concentration of $100 \mathrm{nM}$. This concentration of Bis XI was found to not significantly alter threshold potential values in untreated neurons $(-14.95 \pm 2.21 \mathrm{mV}$

\section{$10 \mu \mathrm{M}$ Oxycodone $+20 \mathrm{mM}$ Ethanol}

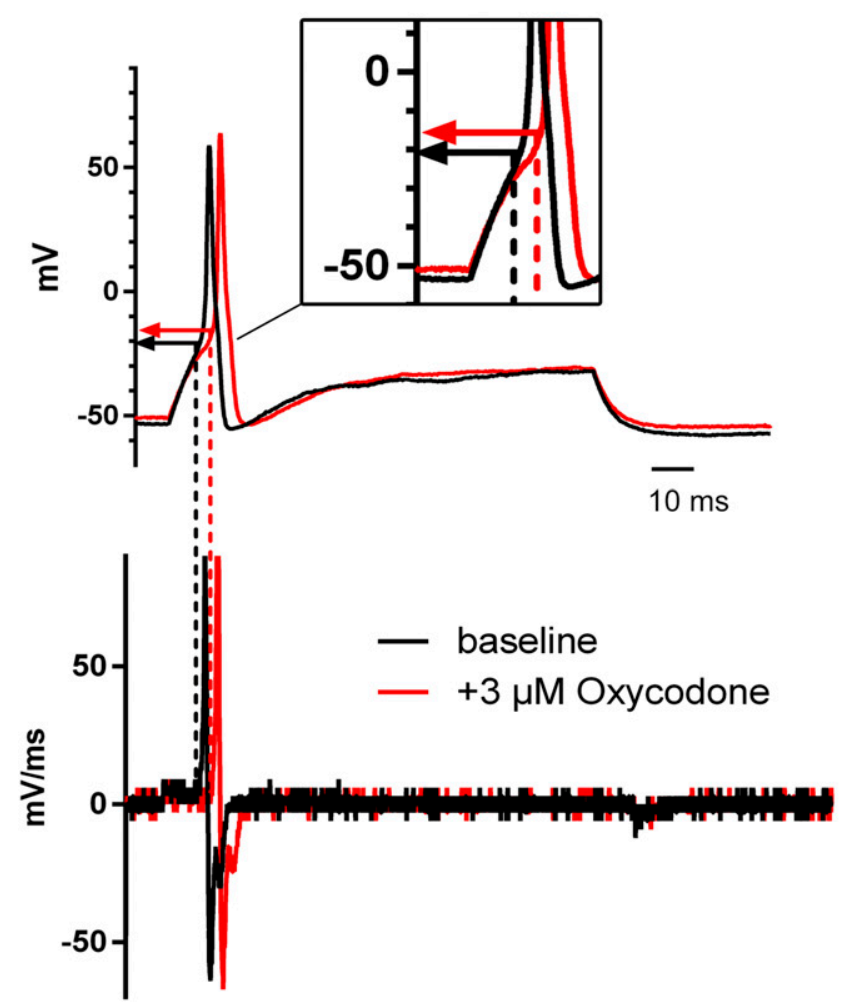

Fig. 6. Representative traces: ethanol reversed oxycodone tolerance following overnight exposure to $10 \mu \mathrm{M}$ oxycodone. Oxycodone tolerance was reversed by a 50-minute pretreatment with $20 \mathrm{mM}$ ethanol, indicated by the shift in threshold potential following a $3 \mu \mathrm{M}$ oxycodone challenge (red) compared with baseline (black).

vs. $-12.30 \pm 1.79$; one-way analysis of variance, $P=0.07, N=$ $1, n=4$ ) (Fig. 7). In neurons exposed to oxycodone overnight and Bis XI in the internal solution, baseline recordings showed these neurons had similar threshold potentials to untreated neurons $(-14.33 \mathrm{mV} \pm 1.67)$, suggesting that the inhibition of PKC eliminated the hyperexcitability state observed in neurons exposed only to $10 \mu \mathrm{M}$ oxycodone (Table 1). Upon exposure to a $3 \mu \mathrm{M}$ oxycodone bath challenge over 10 minutes, neurons containing $100 \mathrm{nM}$ Bis XI internally showed a robust decrease in excitability $(+4.67 \pm 1.00 \mathrm{mV}$ change; $P<0.05)$ (Fig. 8). The response to an oxycodone challenge was similar to both neurons representing acute oxycodone conditions and neurons treated with $10 \mu \mathrm{M}$ oxycodone and ethanol (Fig. 9). The rate at which oxycodone tolerance reversal occurred in the experiments with Bis XI suggests that the mechanism(s) underlying reversal by PKC inhibition are rapid (Fig. 10A). These findings corroborate in vivo findings where administration of a PKC inhibitor reversed tolerance to morphine in mice (Smith et al., 1999; Javed et al., 2004; Withey et al., 2017).

\section{Discussion}

These studies represent the first reported findings of oxycodone's effects in murine DRG neurons. Opioids, including oxycodone, are primarily thought to elicit their antinociceptive effects through both central and peripheral mechanisms; however, tolerance to that effect has predominantly been studied with a focus on mechanisms within the central 


\section{Control Threshold Potentials}

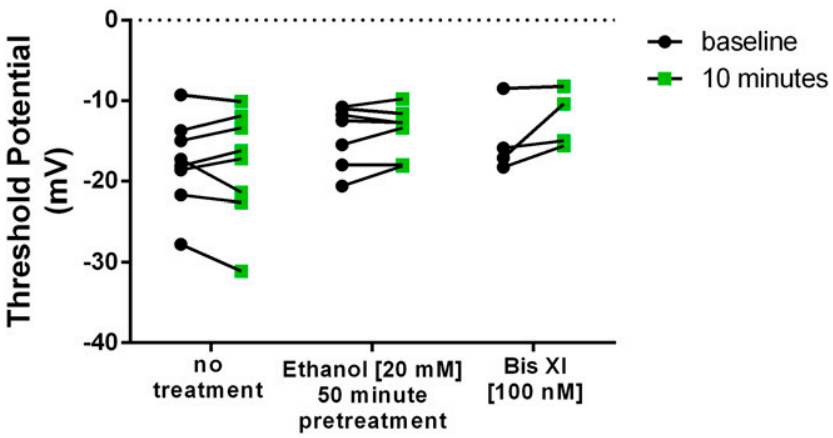

Fig. 7. Control threshold potential values. Control threshold potential values were recorded in the absence of oxycodone in neurons that were isolated and grown in untreated media. In naive DRG neurons $(N=5, n=$ 8), threshold potential values at baseline and 10 minutes later are displayed in the left column (no treatment) and demonstrate no changes occurred in neuronal excitability. To determine if ethanol alone altered threshold potential values in untreated DRG neurons, $20 \mathrm{mM}$ ethanol (final) was added to the media for 50 minutes prior to recording on these neurons $(N=2, n=7)$. Threshold potential values (shown in the middle column) were not affected by this ethanol pretreatment, as determined by no significant shift between values measured at baseline and 10 minutes following baseline recordings. Untreated DRG neurons that were exposed to the PKC inhibitor Bis XI ( $100 \mathrm{nM})$ via the internal solution $(N=1, n=4)$ showed no significant differences in threshold potential values as shown in the right column 10 minutes following baseline recordings. Data were analyzed via two-way repeated measures analysis of variance with Bonferroni's post-hoc test; for each control condition, $P>0.05$.

nervous system (Patrick et al., 1975; Hull et al., 2010). DRG sit in the periphery, adjacent to the spinal cord, just outside the blood-brain barrier. Here, we show that tolerance developed to the acute effects of oxycodone at the level of a single DRG neuron. Our subsequent aim investigated whether ethanol or a PKC inhibitor could reverse tolerance to oxycodone in DRG neurons since they each have previously been shown to reverse various morphine tolerances both in vivo and in vitro (Bailey et al., 2009; Hull et al., 2010, 2013; Llorente et al., 2013; Hill et al., 2016). We found that neurons exposed to either ethanol or the PKC inhibitor, Bis XI, responded to $3 \mu \mathrm{M}$ oxycodone despite a prior overnight exposure to oxycodone, indicating tolerance to oxycodone had been reversed.

The Effect of Acute Oxycodone on Dorsal Root Ganglia Neuron Excitability. We found an acute effect of $3 \mu \mathrm{M}$ oxycodone on threshold potential and AP amplitude. These two characteristics have previously been reported to change following the acute application of morphine on DRG neurons, suggesting that oxycodone acts like morphine and likely works through similar mechanisms at the cellular level (Kang et al., 2017). Other cell parameters, such as resting membrane potential and input resistance, were not affected by acute oxycodone, which agrees with published studies on morphine's effects in both central and peripheral neurons (Siggins and Zieglgänsberger, 1981; Ross et al., 2012). One explanation for the reduced excitability following application of morphine, and now oxycodone, is the reduction in available sodium channels. Only one other study has attempted to investigate the role of oxycodone on sodium channels, where tetrodotoxin (TTX)-resistant sodium channels were specifically evaluated (Osawa et al., 2007). It was found that oxycodone continued to reduce the maximum sodium current output in rat DRG neurons pretreated with TTX, and that it

\section{$10 \mu \mathrm{M}$ Oxycodone $+100 \mathrm{nM}$ Bis $\mathrm{XI}$}

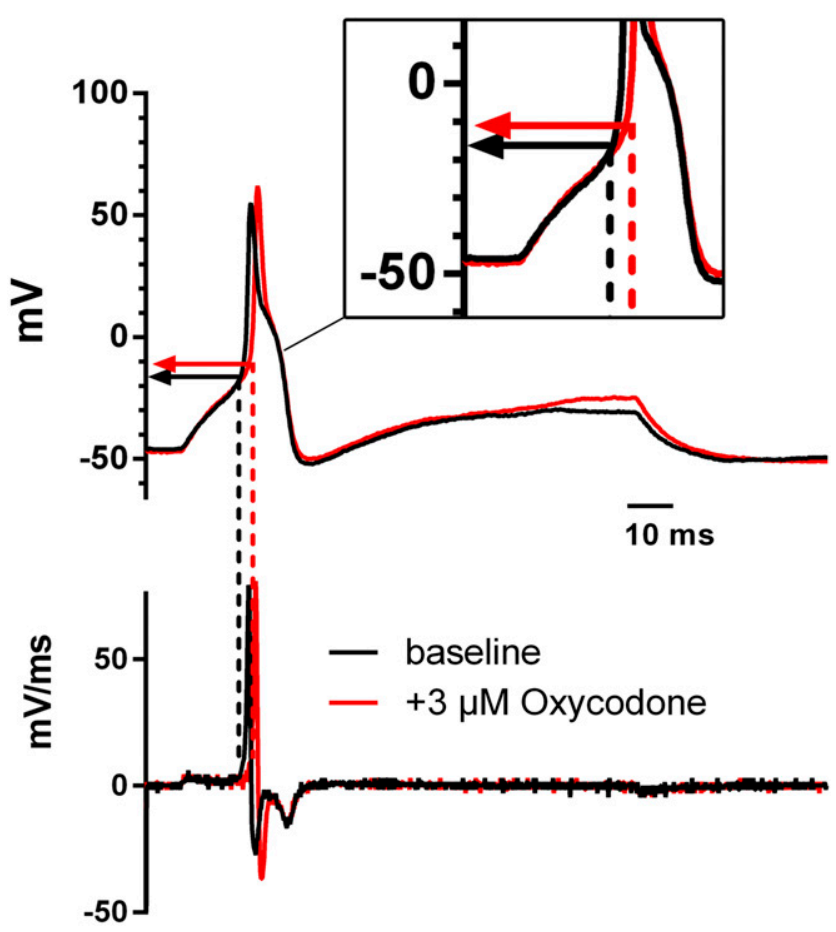

Fig. 8. Representative traces: inhibition of PKC reversed oxycodone tolerance following overnight exposure to $10 \mu \mathrm{M}$ oxycodone. Oxycodone tolerance was reversed upon immediate exposure to $100 \mathrm{nM}$ Bis XI, as indicated by the shift in threshold potential following a $3 \mu \mathrm{M}$ oxycodone challenge (red), compared with baseline (black).

was mediated via opioid receptor independent pathway(s) since naloxone did not prevent the reduced current elicited by oxycodone. Furthermore, much higher concentrations of oxycodone were used than in our studies, ranging from $10 \mu \mathrm{M}$ to $10 \mathrm{mM}$. However, we observed that when either $300 \mathrm{nM}$ naloxone or $100 \mathrm{nM}$ CTAP was co-perfused with $3 \mu \mathrm{M}$ oxycodone, the acute response to oxycodone was blocked. This suggests that in DRG neurons, when both TTX-sensitive and TTX-resistant sodium channels are available, neuronal excitability is affected by acute oxycodone in a $\mu$-opioid receptordependent manner.

The Effects of Prolonged Exposure to Oxycodone. Tolerance to oxycodone at the single-cell level using DRG neurons has not been shown prior to our studies presented here. We developed a model of in vitro tolerance by incubating neurons in media containing $10 \mu \mathrm{M}$ oxycodone for at least 18 hours, which was validated by demonstrating that tolerance to either oxycodone or morphine was abated in $\beta$-arr2 KO mice. When WT neurons were challenged with $3 \mu \mathrm{M}$ oxycodone following exposure to oxycodone overnight, these neurons showed no response. We then found that a $3 \mu \mathrm{M}$ challenge concentration of oxycodone continued to shift the threshold potential and thus reduce neuronal excitability in $\beta$-arr2 KO neurons, which is consistent with the premise that tolerance to opioids is prevented in these $\mathrm{KO}$ mice. The fact that tolerance was observed in isolated DRGs suggests that reduced antinociceptive responses in vivo following repeated oxycodone treatment could be influenced not only by tolerant 


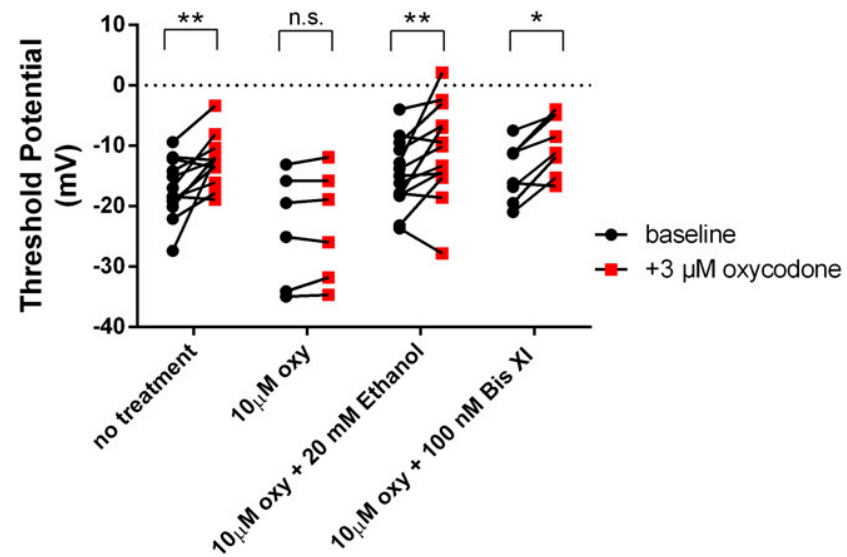

Fig. 9. Threshold potentials in response to $3 \mu \mathrm{M}$ oxycodone. Ten minutes following bath application of $3 \mu \mathrm{M}$ oxycodone (Oxy) led to a significant increase in threshold potentials in untreated DRG neurons $(* * P<0.01)$, and in neurons treated overnight with $10 \mu \mathrm{M}$ oxycodone and either $20 \mathrm{mM}$ ethanol ( $* * P<0.01)$ or $100 \mathrm{nM}$ Bis XI ( $* P<0.05$; n.s., non significant.). Data represent individual changes in threshold potentials before $(\bullet)$ and 10 minutes after (red $\bullet$ ) oxycodone exposure. Statistical significance was considered if $P<0.05$ following analysis by a two-way repeated measures analysis of variance with Bonferroni's post-hoc test. Acute oxycodone data are the same as shown in Fig. 2.

$\mu$-opioid receptors in central neuron populations but also those expressed in peripheral neuronal populations. This idea was further supported by the observation that DRG neurons excised from mice made tolerant to oxycodone in vivo using a single-day tolerance model did not respond to an oxycodone bath challenge the following day, which demonstrated a persistence of tolerance at the single cell level following in vivo treatment alone.

Reversal of Tolerance to Oxycodone by Ethanol or a PKC Inhibitor. Our data showed a robust reversal of oxycodone tolerance by a low concentration of ethanol $(20 \mathrm{mM})$ in
DRG neurons, suggesting that the mechanisms of ethanol reversal occur via intracellular signaling pathways independent of pharmacokinetic influences or neuronal signaling networks. Most states enforce a legal driving limit for blood alcohol concentrations to $0.08 \%$ or lower, which corresponds to approximately $17 \mathrm{mM}$ ethanol (Miller, 2013), suggesting that the reversal of tolerance does not require consumption of excessive amounts of alcohol or extremely high blood alcohol concentrations. This concentration of ethanol was also sufficient to reverse morphine tolerance in locus coeruleus neurons (Llorente et al., 2013), indicating that the mechanisms underlying the reversal of opioid tolerance are functional in multiple neuronal populations.

To our knowledge, the effect of inhibiting PKC or its specific isoforms on oxycodone tolerance has not been investigated in DRG neurons. By applying the PKC inhibitor Bis XI in the internal pipette solution, we were able to demonstrate that inhibiting PKC in neurons exposed to oxycodone overnight led to a rapid reversal of tolerance, due to the continued response to a $3 \mu \mathrm{M}$ oxycodone challenge. Based on published $\mathrm{IC}_{50}$ calculations, this concentration of Bis XI (100 nM) selectively inhibits two isoforms: the conventional isoform, $\operatorname{PKC} \alpha$, and the novel isoform, $\mathrm{PKC} \varepsilon$, with a 10 -fold selectivity for $\mathrm{PKC} \alpha$ over PKCe (Wilkinson et al., 1993). These isoforms have previously been identified as having important roles in maintaining opioid tolerance and have been implicated in having potential interactions with ethanol (Bailey et al., 2006, 2009; Smith et al., 2007; Wilkie et al., 2007). These data highlight the fact that like morphine, oxycodone tolerance mechanism(s) at the neuronal level contain a PKC-mediated component and can be reversed by direct and selective inhibition of $\mathrm{PKC} \alpha$ and $\mathrm{PKC} \varepsilon$ isoforms. Furthermore, the data suggest that ethanol reversal of oxycodone tolerance could also involve a PKC-mediated mechanism, particularly since inhibitors of other known ethanol targets $\left(\mathrm{GABA}_{\mathrm{A}}\right.$,

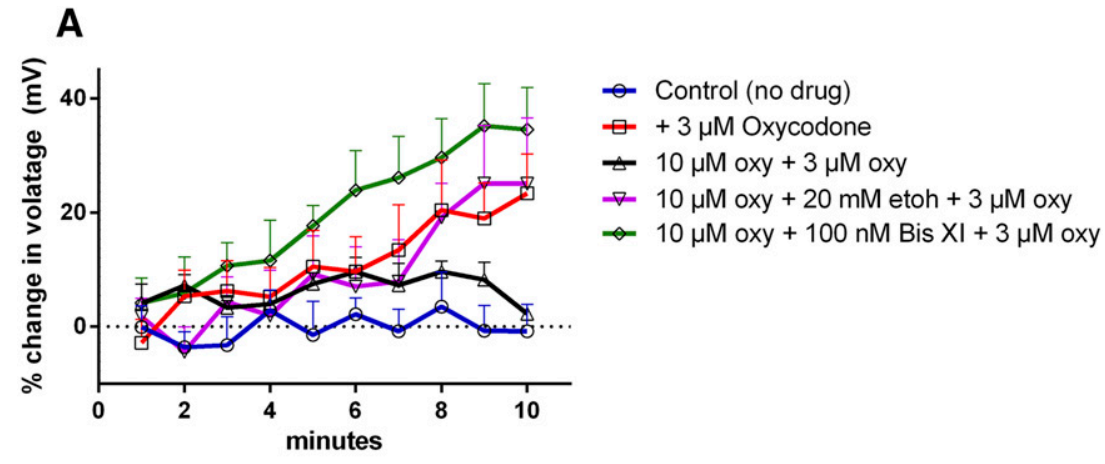

B

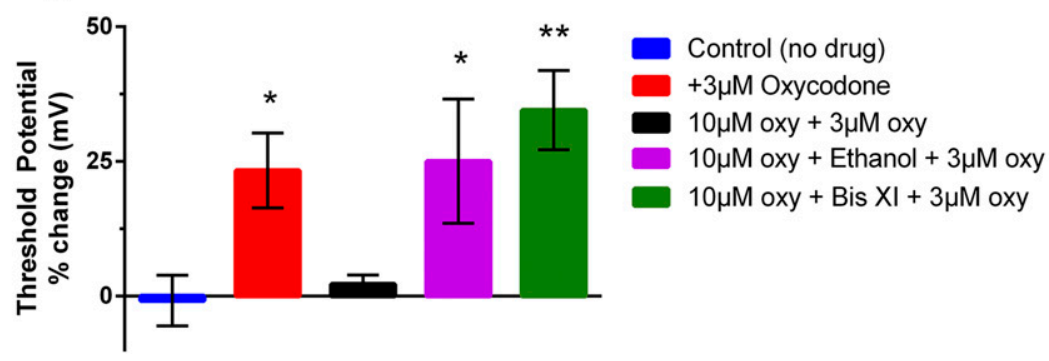

Fig. 10. Time-dependent response in threshold potentials to $3 \mu \mathrm{M}$ oxycodone. Onset of the observed effects of oxycodone occurred within minutes following initial bath exposure (A) and the mean percent change in threshold potential between time 0 and 10 minutes (B) was calculated and analyzed using repeated measures two-way analysis of variance with Bonferroni's post-hoc test. Threshold potentials increased in response to an external bath solution containing $3 \mu \mathrm{M}$ oxycodone in untreated DRG neurons $(\square)(* P<0.05 ; N=7, n=12)$, and in neurons pretreated with $10 \mu \mathrm{M}$ oxycodone that were exposed to $20 \mathrm{mM}$ ethanol $(\nabla)\left({ }^{*} P<0.05 ; N=8, n=\right.$ $12)$ or $100 \mathrm{nM}$ Bis XI $(\diamond)(* * P<0.01 ; N=3, n=8)$. Overnight treatment with $10 \mu \mathrm{M}$ oxycodone $(\triangle)$ led to tolerance to the effects of $3 \mu \mathrm{M}$ oxycodone $(P>0.05 ; N=$ $4, n=6)$. No changes in threshold potential were observed over the 10-minute recording time in control neurons $(\bigcirc)$ that were not exposed to oxycodone $(P>$ $0.05 ; N=6, n=8$ ) 
$N$-methyl-D-aspartate receptors, and L-type calcium channels) did not prevent reversal of morphine tolerance when tested in locus coeruleus neurons (Llorente et al., 2013).

Our conclusions from these studies are that oxycodone similarly reduced DRG neuronal excitability with the same potency as reported for morphine, and that prolonged exposure led to tolerance at the level of a single neuron. The onset of these acute observations occurred within minutes and was $\mu$-opioid receptor dependent. We found that concentrations of ethanol, equivalent to moderately intoxicating doses in humans, completely reversed oxycodone tolerance. Additionally, we showed that reversal of oxycodone tolerance is, in part, mediated by inhibition of PKC. Collectively these studies provide additional insight into the reversal mechanisms of oxycodone tolerance by ethanol, indicating that this phenomenon is neither limited to central neuron populations nor requires external influences such as pharmacokinetic factors or intact neuronal networks.

\section{Authorship Contributions}

Participated in research design: Jacob, Henderson, Dewey, Akbarali.

Conducted experiments: Jacob, Sakakibara, Mischel.

Performed data analysis: Jacob, Sakakibara.

Wrote or contributed to the writing of the manuscript: Jacob, Sakakibara, Henderson, Dewey, Akbarali.

\section{References}

Abraira VE and Ginty DD (2013) The sensory neurons of touch. Neuron 79:618-639. Bailey CP, Oldfield S, Llorente J, Caunt CJ, Teschemacher AG, Roberts L, McArdle CA, Smith FL, Dewey WL, Kelly E, et al. (2009) Involvement of $\mathrm{PKC} \alpha$ and G-protein-coupled receptor kinase 2 in agonist-selective desensitization of $\mu$-opioid receptors in mature brain neurons. Br J Pharmacol 158:157-164.

Bailey CP, Smith FL, Kelly E, Dewey WL, and Henderson G (2006) How important is protein kinase $\mathrm{C}$ in $\mu$-opioid receptor desensitization and morphine tolerance? Trends Pharmacol Sci 27:558-565.

Barabas ME, Mattson EC, Aboualizadeh E, Hirschmugl CJ, and Stucky CL (2014) Chemical structure and morphology of dorsal root ganglion neurons from naive and inflamed mice. J Biol Chem 289:34241-34249.

Bohn LM, Gainetdinov RR, Lin FT, Lefkowitz RJ, and Caron MG (2000) $\mu$-Opioid receptor desensitization by $\beta$-arrestin-2 determines morphine tolerance but not dependence. Nature 408:720-723.

Coderre TJ and Rollman GB (1983) Naloxone hyperalgesia and stress-induced analgesia in rats. Life Sci 32:2139-2146.

Coggeshall RE, Zhou S, and Carlton SM (1997) Opioid receptors on peripheral sensory axons. Brain Res 764:126-132

Corder G, Tawfik VL, Wang D, Sypek EI, Low SA, Dickinson JR, Sotoudeh C, Clark JD, Barres BA, Bohlen CJ, et al. (2017) Loss of $\mu$ opioid receptor signaling in nociceptors, but not microglia, abrogates morphine tolerance without disrupting analgesia. Nat Med 23:164-173.

Gutstein HB and Trujillo KA (1993) MK-801 inhibits the development of morphine tolerance at spinal sites. Brain Res 626:332-334.

Harris LS and Pierson AK (1964) Some narcotic antagonists in the benzomorphan series. J Pharmacol Exp Ther 143:141-148.

Hill R, Lyndon A, Withey S, Roberts J, Kershaw Y, MacLachlan J, Lingford-Hughes A, Kelly E, Bailey C, Hickman M, et al. (2016) Ethanol reversal of tolerance to the respiratory depressant effects of morphine. Neuropsychopharmacology 41:762-773.

Hull LC, Gabra BH, Bailey CP, Henderson G, and Dewey WL (2013) Reversal of morphine analgesic tolerance by ethanol in the mouse. J Pharmacol Exp Ther 345: 512-519.

Hull LC, Llorente J, Gabra BH, Smith FL, Kelly E, Bailey C, Henderson G, and Dewey WL (2010) The effect of protein kinase C and G protein-coupled receptor kinase inhibition on tolerance induced by $\mu$-opioid agonists of different efficacy. J Pharmacol Exp Ther 332:1127-1135.

Jacob JC, Poklis JL, Akbarali HI, Henderson G, and Dewey WL (2017) Ethanol reversal of tolerance to the antinociceptive effects of oxycodone and hydrocodone. $J$ Pharmacol Exp Ther 362:45-52.

Javed RR, Dewey WL, Smith PA, and Smith FL (2004) PKC and PKA inhibitors reverse tolerance to morphine-induced hypothermia and supraspinal analgesia in mice. Eur J Pharmacol 492:149-157.

Kang M, Mischel RA, Bhave S, Komla E, Cho A, Huang C, Dewey WL, and Akbarali HI (2017) The effect of gut microbiome on tolerance to morphine mediated antinociception in mice. Sci Rep 7:42658.

Llorente J, Withey S, Rivero G, Cunningham M, Cooke A, Saxena K, McPherson J, Oldfield S, Dewey WL, Bailey CP, et al. (2013) Ethanol reversal of cellular tolerance to morphine in rat locus coeruleus neurons. Mol Pharmacol 84:252-260.

Miller PM (2013) Biological Research on Addiction: Comprehensive Addictive Behaviors and Disorders, vol 2, 2nd ed, Academic Press, San Diego, CA.

Osawa Y, Iida H, Tanahashi S, and Dohi S (2007) Opioid receptor independent effects of oxycodone on TTX-R Na+ currents in rat sensory neurons, in Proceedings of the Anesthesiology Annual Meeting, 2007 October 13-17; San Francisco, CA, American Society of Anesthesiologists, San Francisco, CA.

Patrick GA, Dewey WL, Spaulding TC, and Harris LS (1975) Relationship of brain morphine levels to analgesic activity in acutely treated mice and rats and in pellet implanted mice. J Pharmacol Exp Ther 193:876-883.

Puig S and Gutstein HB (2017) Opioids: keeping the good, eliminating the bad. Nat Med 23:272-273.

Raehal KM and Bohn LM (2011) The role of beta-arrestin2 in the severity of antinociceptive tolerance and physical dependence induced by different opioid pain therapeutics. Neuropharmacology 60:58-65.

Ross GR, Gade AR, Dewey WL, and Akbarali HI (2012) Opioid-induced hypernociception is associated with hyperexcitability and altered tetrodotoxin-resistant $\mathrm{Na}^{+}$channel function of dorsal root ganglia. Am J Physiol Cell Physiol 302: C1152-C1161.

Siggins GR and Zieglgänsberger W (1981) Morphine and opioid peptides reduce inhibitory synaptic potentials in hippocampal pyramidal cells in vitro without alteration of membrane potential. Proc Natl Acad Sci USA 78:5235-5239.

Smith FL, Gabra BH, Smith PA, Redwood MC, and Dewey WL (2007) Determination of the role of conventional, novel and atypical PKC isoforms in the expression of morphine tolerance in mice. Pain 127:129-139.

Smith FL, Javed RR, Elzey MJ, and Dewey WL (2003) The expression of a high level of morphine antinociceptive tolerance in mice involves both PKC and PKA. Brain Res 985:78-88.

Smith FL, Lohmann AB, and Dewey WL (1999) Involvement of phospholipid signal transduction pathways in morphine tolerance in mice. $\mathrm{Br} J$ Pharmacol 128: $220-226$.

Smith TH, Grider JR, Dewey WL, and Akbarali HI (2012) Morphine decreases enteric neuron excitability via inhibition of sodium channels. PLoS One 7:e45251.

Stein C (2013) Opioid receptors on peripheral sensory neurons, in Madame Curie Bioscience Database, Landes Bioscience, Austin, TX.

Wang HB, Zhao B, Zhong YQ, Li KC, Li ZY, Wang Q, Lu YJ, Zhang ZN, He SQ, Zheng $\mathrm{HC}$, et al. (2010) Coexpression of $\delta$ - and $\mu$-opioid receptors in nociceptive sensory neurons. Proc Natl Acad Sci USA 107:13117-13122.

Wilkie MB, Besheer J, Kelley SP, Kumar S, O’Buckley TK, Morrow AL, and Hodge CW (2007) Acute ethanol administration rapidly increases phosphorylation of conventional protein kinase $\mathrm{C}$ in specific mammalian brain regions in vivo. Alcohol Clin Exp Res 31:1259-1267.

Wilkinson SE, Parker PJ, and Nixon JS (1993) Isoenzyme specificity of bisindolylmaleimides, selective inhibitors of protein kinase C. Biochem $J \mathbf{2 9 4}$ 335-337.

Williams JT, Ingram SL, Henderson G, Chavkin C, von Zastrow M, Schulz S, Koch T, Evans CJ, and Christie MJ (2013) Regulation of $\mu$-opioid receptors: desensitization, phosphorylation, internalization, and tolerance. Pharmacol Rev 65: $223-254$.

Withey SL, Hill R, Lyndon A, Dewey WL, Kelly E, and Henderson G (2017) Effect of tamoxifen and brain-penetrant protein kinase $\mathrm{C}$ and c-Jun N-Terminal kinase inhibitors on tolerance to opioid-induced respiratory depression in mice. $J$ Pharmacol Exp Ther 361:51-59.

Address correspondence to: Hamid I. Akbarali and Joanna Jacob, Department of Pharmacology and Toxicology, Virginia Commonwealth University, 1112 East Clay Street, Richmond, VA 23298-0613. E-mail: hamid.akbarali@vcuhealth.org or jacobjc@vcu.edu 